\title{
Variations in expression of episodic growth by in vitro- cultured shoots of oak (Quercus robur L.)
}

\author{
J.M. Favre and B. Juncker \\ Université de Nancy I, Laboratoire de Biologie des Ligneux, BP 239, 54506 Vandouvre-les-Nancy \\ Cedex, France
}

\section{Introduction}

Under natural conditions, or controlled conditions such as $25^{\circ} \mathrm{C}$ long days, shoots of $Q$. robur exhibit episodic growth. They grow by successive flushes that are composed of an elongation period, 12-14 d long, followed by a rest period, 6-8 d long.

During the rest period, elongation stops, but leaf initiation is only reduced. Consequently, one flush is composed of 2 kinds of leaves: 1) leaves formed during the rest period of the previous flush called preformed leaves; and 2) leaves formed during the elongation period called newformed leaves.

Usually the former represent about $60 \%$ of the total number of leaves per flush, the latter about $40 \%$. These leaves differentiate successively into scale leaves and photosynthetic leaves (Champagnat et al., 1986).

\section{Results}

Under in vitro conditions, variation occurs in the expression of the episodic growth.
Three main shoot growth patterns were obtained, depending upon the culture media.

On media composed of a half-strength Murashige and Skoog (MS) (1962) solution with 1/4 $\mathrm{NH}_{4} \mathrm{NO}_{3}$, or full-strength Gresshof and Doy (GD) (1972) solution, both supplemented with activated charcoal $(A C)$, episodic growth was maintained. Several flushes developed (Fig. 1a). Shoot growth was more robust from primary explants, than from subcultured explants. However, in both cases each flush expanded a number of leaves which corresponded to the primordia content of the initial buds. All the leaves were thus preformed. The potential for subculture of these shoots was poor. The multiplication rate was about 0.5 every 6 wk and cloning failed rapidly.

On media composed of the same mineral solutions but containing benzyladenine (BA), instead of $A C, 2$ different growth patterns occurred. a) In most cases, shoot elongation stopped after $1 \mathrm{mo}$ in culture. A single flush was obtained with 2-3 times as many leaves as were contained in the initial buds. Therefore, each flush bore $50-60 \%$ new-formed leaves (Fig. $\left.1 b_{\oplus}\right)$. Occasionally, a second 


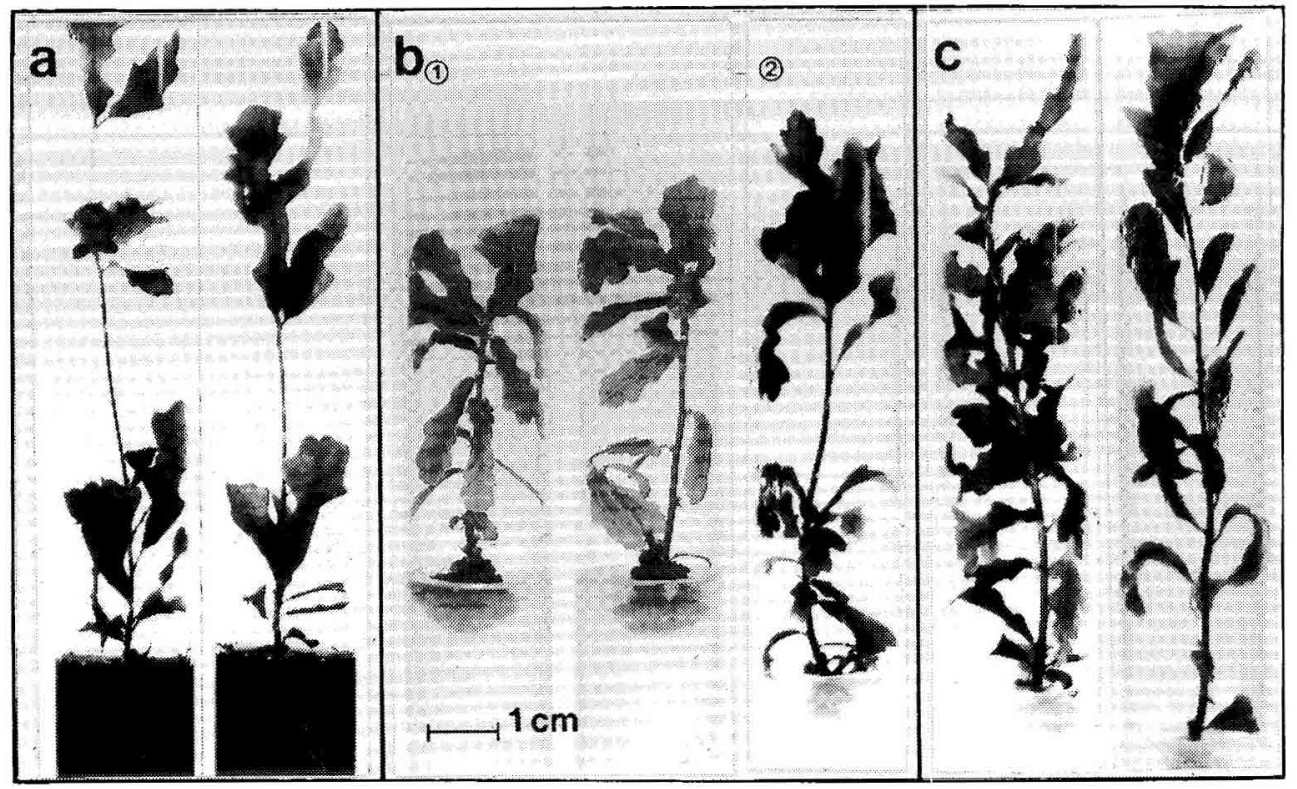

Fig. 1. In vitro shoot growth pattern on different media. a. Episodic growth on media containing AC. b. Single flushes obtained on media containing BA (1). Development of a second flush (2). c. Non-episodic growth on modified MS with BA.

flush developed from these subcultured explants (Fig. $\left.1 b_{(2)}\right)$. Shoots of this growth pattern could be subcultured and cloned satisfactorily. The multiplication rate was 2-4 every $6 \mathrm{wk}$, depending upon the clone. Among the 20 clones tested, the frequency of this shoot growth pattern was $100 \%$ on GD solution and $80 \%$ on halfstrength MS solution.

On media composed of half-strength MS with BA, a third shoot growth pattern occurred in about $20 \%$ of the clones. Shoots elongated continuously. After 2 mo in culture, elongation decreased, probably due to starvation. Within this growth period, no more scale leaves were formed. However, shoots had 5-7 times as many photosynthetic leaves as the primordia content of the initial buds (Fig. 1c). Therefore, $80-90 \%$ of the leaves were newformed leaves. Finally, in these shoots, episodic growth seemed to be abolished. These non-episodic shoots could be subcultured. During 2-3 consecutive subcultures, they continued to express non-episodic growth. However, this was followed by a decline of the culture, apical necrosis and failure to clore. This evolution could be stopped by transfer of cultures onto media poor in totál $\mathrm{N}$ and $\mathrm{NH}_{4}$, such as MS with a diluted concentration of $\mathrm{NH}_{4} \mathrm{NO}_{3}$ or Knop's solution. Reversion to growth pattern 2 could be obtained and potential for micropropagation recovered.

\section{Discussion and Conclusion}

These results point out the importance of 2 components of the culture medium in controlling the shoot growth pattern and the potential for in vitro propagation. 
The first component is $B A$

Without BA, growth was episodic. However, leaf initiation was restricted to the rest period of the buds. Shoot elongation and leaf initiation followed each other. Therefore, this kind of episodic growth differed from that obtained under natural conditions. When BA was added, leaf initiation increased and occurred simultaneously with elongation. Depending upon the clone, this resulted in a shoot growth pattern that was similar to what happens under natural conditions, or in non-episodic growth. Therefore, BA is one of the main factors controlling the shoot growth pattern of oak in vitro.

The second component is nitrogen or, more precisely, the $\mathrm{NH}_{4}$ concentration

We have seen that non-episodic growth occurred only on half-strength MS solution, i.e., on the medium with the highest $\mathrm{N}$ and $\mathrm{NH}_{4}$ concentrations. Since it was possible to reverse non-episodic shoots to episodic ones by transfer onto a medium with low nitrogen and ammonium concentrations, the nitrogen composition of the medium must also play a role in the control of the growth pattern under in vitro conditions.

In summary, the growth pattern of oak in vitro appeared to be mainly controlled by the cytokinins and nitrogen composition of the culture medium.

\section{References}

Champagnat P., Payan E., Champagnat M., Barnola P., Lavarenne S. \& Bertholon C. (1986) La croissance rythmique de jeunes chênes pédonculés cultivés en conditions contrôlées et uniformes. Nat. Monspel. Coll. International sur l'Arbre, Montpellier Sept 1985. 303-337

Gresshoff P.M. \& Doy C.H. (1972) Development and differentiation of haploid Lycopersicon esculentum (tomato). Planta 107, 161-170

Murashige T. \& Skoog F. (1962) A revised medium for rapid growth and bioassays with tobacco tissue cultures. Physiol. Plant. 15, 473497 